\title{
Enhancing Light Absorption and Charge Transfer Efficiency in Carbon Dots Through Graphitization and Core Nitrogen Doping
}

\author{
Benjamin C. M. Martindale, ${ }^{[\mathrm{a}]}$ Georgina A. M. Hutton, ${ }^{[\mathrm{a}]}$ Christine A. Caputo, ${ }^{[\mathrm{a}]}$ Sebastian Prantl, ${ }^{[\mathrm{b}]}$ \\ Robert Godin, ${ }^{[b]}$ James R. Durrant, ${ }^{[b]}$ and Erwin Reisner*[a]
}

\begin{abstract}
Single-source precursor syntheses have been devised for the preparation of structurally similar graphitic carbon dots (CDs), with $(g-\mathrm{N}-\mathrm{CD})$ and without $(g-\mathrm{CD})$ core nitrogen doping for artificial photosynthesis. An order of magnitude improvement has been realized in the rate of solar (AM1.5G) $\mathrm{H}_{2}$ evolution using $g-\mathrm{N}-\mathrm{CD}$ $\left(7950 \mu \mathrm{mol}_{\mathrm{H} 2}\left(\mathrm{~g}_{\mathrm{CD}}\right)^{-1} \mathrm{~h}^{-1}\right)$ compared to undoped CDs. All graphitized CDs show significantly enhanced light absorption compared to amorphous CDs (a-CD) yet undoped $g$-CD display poor photosensitizer ability due to poor extraction of photogenerated charges. Transient absorption spectroscopy showed that nitrogen doping in $\mathrm{g}-\mathrm{N}-\mathrm{CD}$ increases the efficiency of hole scavenging by the electron donor and thereby significantly extends the lifetime of the photogenerated electrons, allowing this material's high absorption coefficient to be translated into high charge transfer efficiency.
\end{abstract}

Carbon dots (CDs) have recently emerged as a low-cost material with promising photocatalytic properties. ${ }^{[1,2]}$ Possessing the properties of UV-visible light absorption, water solubility and high stability whilst being scalable and readily synthesized from abundant precursors, interest in CDs for the replacement of more established light absorbers used in hybrid photocatalytic systems is burgeoning. ${ }^{[2]}$ The use of CDs as photosensitizer in a noble-metal free system for solar $\mathrm{H}_{2}$ evolution was recently reported, however, the overall system performance (specific activity, quantum yield) was low compared to state-of-the-art light absorbers. ${ }^{[3]}$ Control over CD structure is a key objective to tune their properties for specific applications.

The composition of the $C D$ core varies from amorphous to graphitic depending on the temperature of synthesis employed. Generally temperatures above $300^{\circ} \mathrm{C}$ lead to significant graphitization whilst those below result in amorphous particles, ${ }^{[4]}$ unless $\mathrm{sp}^{2} / \mathrm{sp}$ hybridized carbon has been included in the precursor. ${ }^{[5]}$ The origin of light absorption in CDs stems from $\pi-$ $\Pi^{*}(\mathrm{C}=\mathrm{C})$ and $\mathrm{n}-\Pi^{*}(\mathrm{C}=\mathrm{O})$ transitions in the core and on the surface of the particles. ${ }^{[6]}$ Graphitization of the CD core should therefore have a large impact on their light harvesting ability. However, the effect of $C D$ graphitization on the photophysical and resulting photocatalytic properties has not been studied.

CDs doped with heteroatoms, predominantly nitrogen, have been reported previously. ${ }^{[7-9]}$ They are typically synthesized by hydrothermal treatment of a mixture carbonaceous and nitrogenous precursors (such as citric acid and ethylenediamine or urea). ${ }^{[7,9]}$ The resulting 'nitrogen-doped' carbon dots are thought to consist primarily of a carbon core with surface defects passivated by amine moieties. ${ }^{[10,11]}$ This has

[a] Dr BCM Martindale, Miss GAM Hutton, Dr CA Caputo, Dr E Reisner Christian Doppler Laboratory for Sustainable SynGas Chemistry Department of Chemistry, University of Cambridge

Lensfield Road, Cambridge CB2 1EW, UK

E-mail: reisner@ch.cam.ac.uk

Homepage: http://www-reisner.ch.cam.ac.uk/

[b] Mr S Prantl, Dr R Godin, Prof JR Durrant

Department of Chemistry, Imperial College London

Exhibition Road, London, SW7 2AZ, UK

Supporting information for this article is given via a link at the end of a significant impact on the photoluminescence properties of such dots where the fluorescence quantum yields are many times higher than carboxylic terminated CDs. ${ }^{[3,7,11]}$ Core nitrogen doping of a $C D$, on the other hand, could have significant effects in the context of photocatalysis through engineering of energy levels or enhancing the efficiency of charge transfer reactions. $^{[12,13]}$ However, no study has been made into the influence of core nitrogen doping on photocatalytic fuel generation using CDs.

This work makes use of a single-source precursor (SSP) approach, ${ }^{[14,15]}$ where features of the molecule are preserved after decomposition to the forming CD. Aspartic acid (Asp), a low-cost and naturally abundant amino acid, was utilized for this purpose (Figure S1). Its molecular structure is similar to that of citric acid, a well-known CD forming precursor, but significantly, also includes a $\mathrm{C}-\mathrm{N}$ bond connecting a nitrogen atom to the carbon chain from which the CD core is produced.

$\mathrm{N}$-doped CDs ( $g$-N-CD) were synthesized by pyrolysis of aspartic acid (Asp) in air at $320^{\circ} \mathrm{C}$ (Figures 1a and S1). Full synthetic and characterization details (TEM, AFM, XRD, Raman, NMR, IR, XPS, TGA-MS, Zeta potential, elemental analysis) can be found in the Supporting Information (Figures S2 - S9). TEM revealed the presence of nanoparticles with an average diameter of $3.1 \pm 1.1 \mathrm{~nm}$ (Figures $1 \mathrm{~b}$ and S2). Height profiles obtained from AFM imaging demonstrate that the particles are quasi-spherical (Figure S3). The powder XRD pattern shows a broad peak centered at $27.0^{\circ} 2 \theta$ consistent with a nanocrystalline graphitic structure ${ }^{[16]}$ (Figure S4). Lattice fringes corresponding to the graphitic intralayer spacing (100) of $2.4 \AA$ are observed by TEM (Figure 1b). The Raman spectrum of $g-\mathrm{N}-$ $C D$ is consistent with graphitic content (G-band, $1570 \mathrm{~cm}^{-1}$ ) and
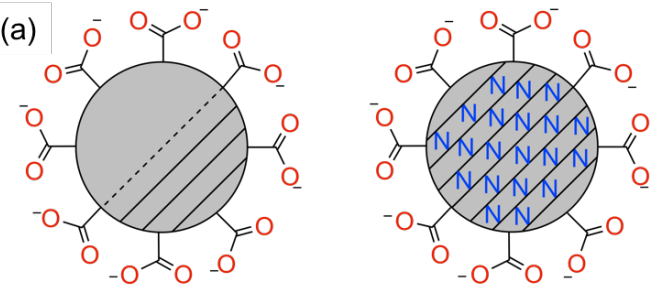

$a-\mathrm{CD} / g-\mathrm{CD}\left(\Delta=180 / 320^{\circ} \mathrm{C}\right)$

$g-\mathrm{N}-\mathrm{CD}\left(\Delta=320^{\circ} \mathrm{C}\right)$
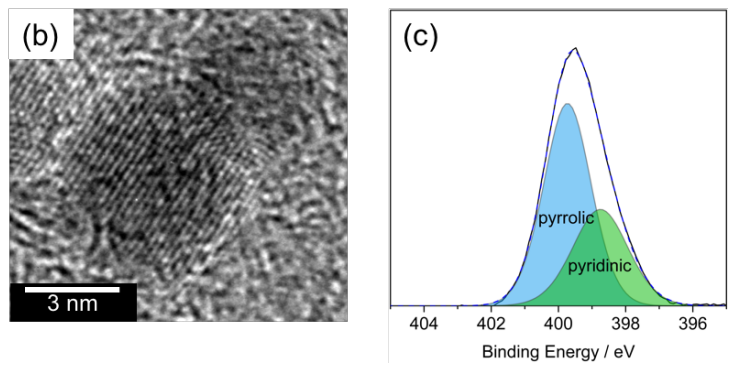

Figure 1. (a) Structure of CDs used in this study. (b) TEM image of a $g-\mathrm{N}-\mathrm{CD}$ particle at high magnification. (c) High resolution XPS spectrum (baseline corrected) of the N1s region of $g-\mathrm{N}-\mathrm{CD}$ with peak deconvolution. 
defects (D-band, $1340 \mathrm{~cm}^{-1}$; Figure S5). ${ }^{13} \mathrm{C}$ NMR revealed exclusively $\mathrm{sp}^{2}$ environments $(\mathrm{C}=\mathrm{C}$ and $\mathrm{C}=\mathrm{O})$ in the range $\delta=$ $110-180$ ppm with no sp ${ }^{3}$ centers (Figure S6). IR spectroscopy confirmed the presence of carboxylates as the primary surface functionality with major peaks for the symmetric and antisymmetric stretches at $v=1363$ and $1578 \mathrm{~cm}^{-1}$ (Figure S7). This is consistent with the negative zeta potential value $(\zeta=-$ $23 \pm 1 \mathrm{mV}$ ) obtained at $\mathrm{pH} 6$ in agreement with values previously obtained for carboxylic acid coated CDs. ${ }^{[17]}$

${ }^{15} \mathrm{~N}$ NMR spectroscopy (Figure S6) revealed the complete loss of the ${ }^{15} \mathrm{~N}$ (amine) peak in Asp at $\delta=30.7 \mathrm{ppm}$ along with the formation of a set of $\mathrm{sp}^{2} \mathrm{~N}$ peaks in the range $\delta=105-120$ $\mathrm{ppm}$. These peaks are in the range calculated and reported for edge graphite (pyridinic) and pyrrolic nitrogen dopants in a graphitic environment. ${ }^{[18,19]}$ Further, 2D ${ }^{13} \mathrm{C}-{ }^{15} \mathrm{~N}$ correlation NMR (HMQC) experiments (Figure S6) show direct bonding between nitrogen and core graphitic carbon environments in $g-\mathrm{N}-\mathrm{CD}$. A correlation is observed between a lower shift $\mathrm{sp}^{2}{ }^{13} \mathrm{C}$ signal at $129 \mathrm{ppm}$ and a ${ }^{15} \mathrm{~N}$ signal at $107 \mathrm{ppm}$, which can be assigned as a pyrrolic graphite defect. ${ }^{[18]}$ Correlations are also observed between ${ }^{13} \mathrm{C}$ environments between $172-175 \mathrm{ppm}$ and ${ }^{15} \mathrm{~N}$ environments in the range $108-115 \mathrm{ppm}$, which may correspond to pyridinic environments. In agreement, the deconvoluted N1s XPS spectrum consists of two peaks at 398.8 and $399.8 \mathrm{eV}$, which is consistent with previous assignments as pyridinic and pyrrolic nitrogen environments in carbon materials, respectively (Figure 1c). ${ }^{[20,21]}$ Confirmation that nitrogen incorporation occurs in the core of $g-\mathrm{N}-\mathrm{CD}$ demonstrates the success of the SSP approach to control the core structure of thermolytically derived CDs.

Structurally similar but undoped, graphitic CDs ( $g$-CD) with a size of $3.6 \pm 1.0 \mathrm{~nm}$ were synthesized for comparison by pyrolysis of citric acid at $320^{\circ} \mathrm{C}$, as well as the reported undoped, amorphous $\mathrm{CDs}^{[3]}(\mathrm{a}-\mathrm{CD})$ at $180^{\circ} \mathrm{C}$ (see Supporting Information for experimental and characterization details).

The optical properties of the CDs were investigated by UVvisible and photoluminescence $(\mathrm{PL})$ spectroscopy. The UV-vis spectra of $g-\mathrm{N}-\mathrm{CD}, g-\mathrm{CD}$ and $a-\mathrm{CD}$ all show a broad and largely featureless absorption across the near-UV tailing into the visible region (Figure 2a), characteristic of unpassivated CDs. ${ }^{[6]}$ Table $\mathrm{S} 1$ shows the mass and molar extinction coefficients for the CDs at various wavelengths. Both $\mathrm{CDs}$ with graphitic cores $(g-\mathrm{N}-\mathrm{CD}$ and $g$-CD) show significantly increased absorption between 300 $-800 \mathrm{~nm}$ (10 and 20 times, respectively) in comparison to the largely amorphous $a-C D$. The improved absorption of the graphitic CDs is particularly significant at the tail into the visible wavelengths. This effect reflects an increased number of delocalized $\pi-\Pi^{*}(\mathrm{C}=\mathrm{C})$ optical transitions in the core as a result of the high $\mathrm{sp}^{2}$ carbon content of graphitized CDs.

The PL quantum yields for $g-\mathrm{N}-\mathrm{CD}$ and $g-\mathrm{CD}$ were determined at an excitation wavelength of $\lambda=360 \mathrm{~nm}$ to be $1 \%$; low values consistent with unpassivated $C D$ s and in the same range as that reported for a-CD $(2 \%) .{ }^{[3]}$ Similarly, the PL spectra for $g-\mathrm{N}-\mathrm{CD}$ and $g-\mathrm{CD}$ show an excitation wavelength dependent emission profile as previously reported for a-CD (Figure S13). ${ }^{[3]}$ Unlike a-CD, however, $g-\mathrm{N}-\mathrm{CD}$ show a broad excitation spectra with two peaks at 300 and $400 \mathrm{~nm}$, which are tentatively assigned to core and surface/edge excitations, respectively, whereas $a-C D$ shows only one clear excitation maximum at
$360 \mathrm{~nm}$ suggesting only the presence of surface confined fluorophores. $g$-CD only displays one excitation maximum at $300 \mathrm{~nm}$ suggesting that PL results predominantly from core graphitic units, however the broad red tail likely corresponds to the presence of surface states. ${ }^{[22,23]}$ The PL lifetimes of the CDs were measured using time correlated single photon counting (TCSPC) at excitation $\lambda=360 \mathrm{~nm}$ (Figure S14). $g-\mathrm{N}-\mathrm{CD}, g-\mathrm{CD}$ and $a-C D$ all show similar $t_{50 \%}$ half-lives (time at which half of the initial amplitude has decayed) of $1.4,1.5$ and $1.8 \mathrm{~ns}$, respectively.

The capability of the CDs for photoreduction of methyl viologen was studied (see Supporting Information; Figure S15) before photocatalytic $\mathrm{H}_{2}$ evolution was carried out using CDs and the water-soluble molecular $\mathrm{Ni}$ bis(diphosphine) catalyst NiP $^{[24]}$ (structure shown in Figure S16) under sacrificial aqueous conditions and simulated solar irradiation (AM1.5G). Full details and additional photocatalytic experiments can be found in the Supporting Information (Figures S16 - S22). The system variables (amount of $\mathrm{CD}$, amount of catalyst, sacrificial electron donor and $\mathrm{pH}$ ) were optimized for maximum $\mathrm{H}_{2}$ production per $\mathrm{CD}$ or per catalyst at $25^{\circ} \mathrm{C}$ (Table S3). EDTA and $\mathrm{pH} 6$ were selected as electron donor and $\mathrm{pH}$ respectively (Figures $\mathrm{S} 17$ \& S18) and all further experiments were carried out under these conditions. Control experiments in the absence of $C D$, catalyst or electron donor, with $C D$ precursor in place of $C D$ and metal salt in place of NiP resulted in no $\mathrm{H}_{2}$ evolution (Figure S19). The lack of activity without electron donor indicates that the $\mathrm{sp}^{2}$ nitrogen centers in $g-\mathrm{N}-\mathrm{CD}$ are not able to act as donor sites for the self-quenching of photogenerated holes.

The nitrogen-doped, graphitic CDs showed high per particle performance. An activity of $7775 \mu \mathrm{mol}_{\mathrm{H} 2}\left(\mathrm{~g}_{\mathrm{CD}}\right)^{-1} \mathrm{~h}^{-1}$ was obtained using $0.01 \mathrm{mg}(0.4 \mathrm{nmol}) \mathrm{g}-\mathrm{N}-\mathrm{CD}$ and $10 \mathrm{nmol} \mathrm{NiP}$ (Figure 2b). Similarly, an activity of $7950 \mu \mathrm{mol}_{\mathrm{H} 2}\left(\mathrm{~g}_{\mathrm{CD}}\right)^{-1} \mathrm{~h}^{-1}$ was achieved using $0.1 \mathrm{mg}(4 \mathrm{nmol}) \mathrm{g}-\mathrm{N}-\mathrm{CD}$ and $100 \mathrm{nmol} \mathrm{NiP}$. This $\mathrm{H}_{2}$ evolution rate is the highest reported specific activity for a CD used in photocatalytic $\mathrm{H}_{2}$ production and represents an order-ofmagnitude improvement over undoped a-CD. ${ }^{[2,3,25,26]}$ With decreased catalyst to $C D$ ratio, higher per catalyst performance could be achieved. Optimized conditions resulted in a turnover frequency $\left(\mathrm{TOF}_{\mathrm{Ni}}\right)$ of $143\left(\mathrm{~mol}_{\mathrm{H} 2}\right)\left(\mathrm{mol}_{\mathrm{Ni}}\right)^{-1} \mathrm{~h}^{-1}$ and turnover number $\left(\mathrm{TON}_{\mathrm{Ni}}\right)$ of $277\left(\mathrm{~mol}_{\mathrm{H} 2}\right)\left(\mathrm{mol}_{\mathrm{Ni}}\right)^{-1}$ after $4 \mathrm{~h}$ irradiation using $0.5 \mathrm{mg}(23 \mathrm{nmol}) \mathrm{g}$-N-CD and $10 \mathrm{nmol}$ NiP (Figure S19).

An analogous system prepared using the graphitized but
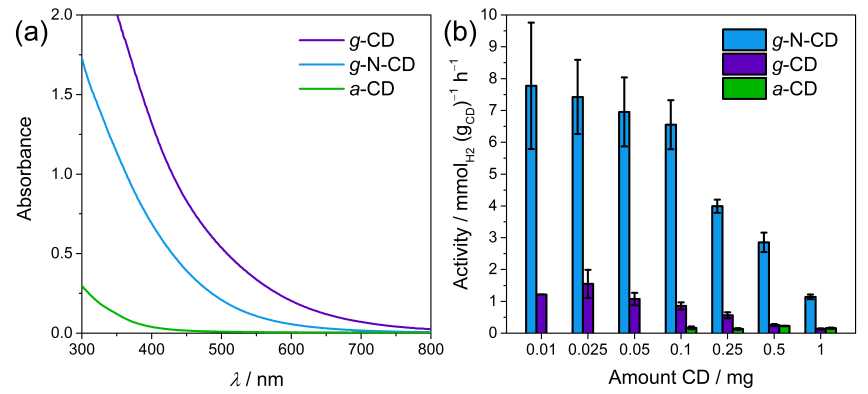

Figure 2. (a) UV-vis absorption spectra of $g-\mathrm{N}-\mathrm{CD}, g-\mathrm{CD}$ and $a-\mathrm{CD}$ (0.1 $\mathrm{mg} \mathrm{mL}^{-1}$ in $\mathrm{H}_{2} \mathrm{O}$ ). (b) Photo- $\mathrm{H}_{2}$ generation using various amounts of $\mathrm{CDs}$ $(0.01-1 \mathrm{mg})$ and $10 \mathrm{nmol} \mathbf{N i P}$ in aqueous EDTA solution $(0.1 \mathrm{M}, \mathrm{pH} 6,3 \mathrm{~mL})$ under simulated solar irradiation (AM 1.5G, $100 \mathrm{~mW} \mathrm{~cm}^{-2}$ ) at $25^{\circ} \mathrm{C}$. 
undoped $g$-CD $(0.5 \mathrm{mg})$ and $\mathrm{NiP}(10 \mathrm{nmol})$ had significantly reduced performance compared to $g-\mathrm{N}-\mathrm{CD}$ with an observed specific activity of $1549 \mu \mathrm{mol}_{\mathrm{H} 2}\left(\mathrm{~g}_{\mathrm{CD}}\right)^{-1} \mathrm{~h}^{-1}$ (Figure 2) and a TOF $\mathrm{Ni}_{\mathrm{Ni}}$ and $\mathrm{TON}_{\mathrm{Ni}}$ of $12 \mathrm{~h}^{-1}$ and $45\left(\mathrm{~mol}_{\mathrm{H} 2}\right)\left(\mathrm{mol}_{\mathrm{Ni}}\right)^{-1}$, respectively (Figure $\mathrm{S} 19)$. However, like $\mathrm{g}-\mathrm{N}-\mathrm{CD}$, as a result of increased light absorption, lower amounts of $g-C D$ are required than $a-C D$ and the specific activity is significantly higher (1549 vs. 226 $\mu \mathrm{mol}_{\mathrm{H} 2}\left(\mathrm{~g}_{\mathrm{CD}}\right)^{-1} \mathrm{~h}^{-1}$; Figure $\left.2 \mathrm{~b}\right)$. When normalizing for absorption, on a per Ni basis, $\mathrm{H}_{2}$ evolution is slightly faster with a-CD (TOF $_{\mathrm{Ni}}$ of $\left.41 \mathrm{~h}^{-1}\right) \cdot{ }^{[3]}$

The $g-\mathrm{N}-\mathrm{CD} / \mathrm{NiP}$ photocatalytic system was further tested under conditions of visible-only light irradiation by equipping the solar light simulator with various longpass filters $(\lambda>400,455$, $495 \mathrm{~nm}$ ) (Figure S20). In all cases the $g$-N-CD/NiP system (0.5 mg g-N-CD) significantly outperforms a-CD/NiP (10 mg aCD), in terms of $\mathrm{TOF}_{\mathrm{Ni}}$, with activity even persisting in the $\lambda>495 \mathrm{~nm}$ region, where no activity occurs in the case of a-CD. It is noteworthy that the concentration of a-CD employed was 20 times greater than $g-\mathrm{N}-\mathrm{CD}$ to compare the systems under similar light harvesting conditions, and that the per gram performance enhancements are substantially greater. The $g-\mathrm{N}-\mathrm{CD} / \mathrm{NiP}$ system under $\lambda>400 \mathrm{~nm}$ irradiation displays a TOF Ni $_{\text {of }} 86 \mathrm{~h}^{-1}$ and $\mathrm{TON}_{\mathrm{Ni}}$ of 185 . This represents $>60 \%$ performance under visible-only compared to full UV-visible spectrum irradiation, which is also an improvement over previous CD and carbonbased photosensitizers. ${ }^{[3,27]}$ The augmented performance agrees with the greatly increased visible light absorption of $g-\mathrm{N}-\mathrm{CD}$.

The external and internal quantum efficiency (EQE and IQE) of the system were determined using a monochromatic light source $\left(\lambda=360 \mathrm{~nm}, \mathrm{FWHM} 10 \mathrm{~nm}, I=4.60 \mathrm{~mW} \mathrm{~cm}^{-2}\right)$. An unoptimized EQE of $5.20 \pm 0.08 \%$, corresponding to an IQE of $5.25 \pm 0.08 \%$, was obtained using $0.5 \mathrm{mg} g-\mathrm{N}-\mathrm{CD}$ and $30 \mathrm{nmol}$ NiP in $3 \mathrm{~mL}$ of EDTA solution $(0.1 \mathrm{M})$ at $\mathrm{pH} 6$. This efficiency is high for a noble and toxic metal free system and significantly higher than that reported for $a-C D / N i P(1.40 \pm 0.08 \%, I Q E) .{ }^{[3]}$

The photophysical properties of the CD systems were investigated using transient absorption spectroscopy (TAS), ${ }^{[28]}$ from femtosecond to second timescales in order to investigate intrinsic relaxation processes, the nature of photogenerated species and charge transfer reactions. fs-TAS experiments revealed that photoexcitation of all $C D$ types gave rise to a transient absorption signal spanning the visible range from 450 $750 \mathrm{~nm}$ decaying on a ps timescale (Figures 3a, S23 and S24). Features are centered near $505 \mathrm{~nm}$ and $650 \mathrm{~nm}$, similar to previous observations. ${ }^{[9,29]}$ It is possible that the shorter and longer wavelength features relate to core and surface states, respectively, as determined for graphene quantum dots. ${ }^{[30]}$ The kinetics at $505 \mathrm{~nm}$ are observed to decay slower than those at $665 \mathrm{~nm}$ (Figure S25), also in line with previous studies and supports the presence of different types of excited states. ${ }^{[30,31]}$

To simplify the comparison of complex decay traces (stretched exponentials on the fs-ns timescale (Figure S26), biphasic behavior on the $\mu s-s$ timescale), the decay kinetics were characterized by $t_{50 \%}$. From fs-TAS measurements, $t_{50 \%}$ is on the order of a few picoseconds (9 ps for $g-\mathrm{N}-\mathrm{CD}$, Figure 4) and does not show excitation fluence dependence (Figure S27), indicating a very fast geminate intrinsic relaxation process which outcompetes bimolecular reactions (100 ps assuming $k_{\text {diff }}=1 \mathrm{x}$ $10^{10} \mathrm{M}^{-1} \mathrm{~s}^{-1}$ and $1 \mathrm{M}$ of reactant). This is the primary restriction
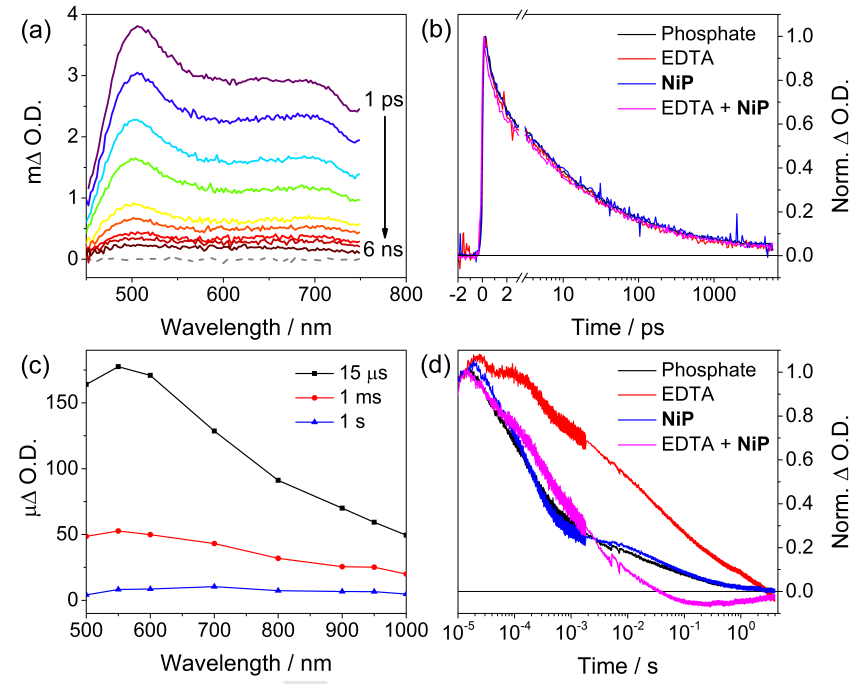

Figure 3. TAS of $g-\mathrm{N}-\mathrm{CD}$. (a) fs-TAS spectra at different delays $(1,5,10,25$, 100, 200, 500 ps, 1, 6 ns; gray dashed line before excitation). (b) Normalized fs-TAS kinetics under various conditions $(\mathrm{pH} \mathrm{6)}$ measured at $505 \mathrm{~nm}$. Samples were excited at $355 \mathrm{~nm}$. (c) $\mu \mathrm{s}$-TAS spectra at different times in $\mathrm{P}_{\mathrm{i}}$ buffer $(\mathrm{pH} 6)$. (d) Normalized $\mu \mathrm{s}-\mathrm{TAS}$ kinetics at $500 \mathrm{~nm}$ under various conditions.

on the overall activity of the system. The fs-TAS kinetics are unchanged in the presence of EDTA and/or NiP (Figure 3b), showing that charge transfer reactions from CDs occur on timescales $>6 \mathrm{~ns}$. Accordingly, we consider charge transfer to occur through a diffusion mechanism, with rate constants lower than diffusion-controlled values, as was observed for quenching by triethanolamine. ${ }^{[9]} \mathrm{A}$ summary of the relaxation and charge transfer timescales determined by TAS is shown in Figure 4.

Importantly, a fraction of species (up to $6 \%$ of the initial amplitude) are significantly longer-lived and remain at a delay time of $6 \mathrm{~ns}$. For the $\mathrm{g}-\mathrm{N}-\mathrm{CD}$ system, this proportion of long-lived species $(6 \%)$ is very close to the IQE $(5.2 \%)$, suggesting almost quantitative yields of the charge extraction from the longlived species. In comparison, $g$-CD shows a lower residual amplitude of about $3 \%$ at $6 \mathrm{~ns}$, limiting the attainable efficiency. Remarkably, using $\mu$ s-TAS, transients could be monitored for several seconds (Figure $3 \mathrm{c}$ ). Although, the nature of excited states in nanoscale systems is complex ${ }^{[32]}$ and remains to be fully elucidated for CDs, lifetimes of seconds are inconsistent with typical nanosecond kinetics of excited singlet states and are more in line with trapped charges in semiconductors ${ }^{[27,28]}$ or potentially long-lived triplet states formed in CDs. ${ }^{[3,34]}$

The addition of EDTA to CDs resulted in an increased lifetime of the $\mu \mathrm{s}$-TAS transients (Figure 3d), particularly at 500 $\mathrm{nm}$ compared to $800 \mathrm{~nm}$ (Figure S28). The increased lifetime is presumed to be caused by extraction of photogenerated holes by EDTA and the spectral feature near $500 \mathrm{~nm}$ is consequently assigned to photogenerated electrons in CD.

Kinetic experiments at $500 \mathrm{~nm}$ show a faster signal decay than at $800 \mathrm{~nm}$ where a second decay phase is apparent $>1 \mathrm{~ms}$ (Figure S28). As a result, the $\mu \mathrm{s}-\mathrm{TAS}$ spectra redshifts from 550 $\mathrm{nm}$ to $700 \mathrm{~nm}$ over $\mu$ s to s timescales (Figure 3d). Furthermore, the $500 \mathrm{~nm}$ feature is rapidly quenched by $\mathrm{O}_{2}(<10 \mu \mathrm{s})$ and the residual signal peaks towards $700 \mathrm{~nm}$ (Figure S29). The addition 


\section{Reductive Quenching Oxidative Quenching}

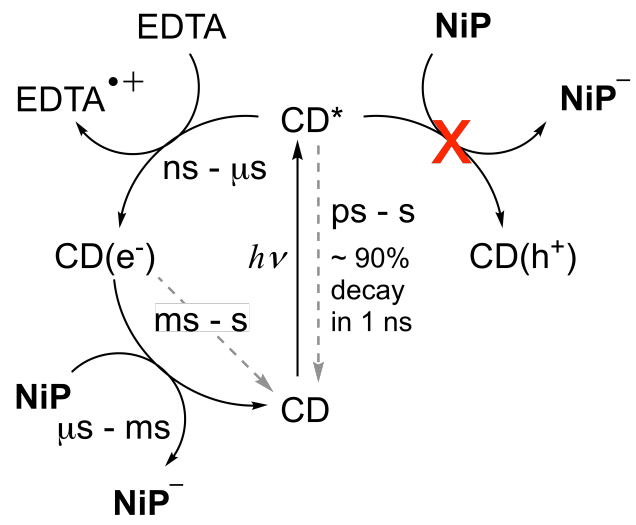

Figure 4. Representative timescales of the relaxation and charge transfer steps and determined reaction mechanism under photocatalytic conditions. Recombination reactions are indicated with gray dashed arrows and productive charge transfer steps with black solid arrows. See Supporting Information for discussion of the determination of these timescales.

of EDTA increased the prominence of the $500 \mathrm{~nm}$ feature on $\mathrm{ms}$ timescales (Figure S30). Interestingly, this $500 \mathrm{~nm}$ spectral feature is more prominent for $g-\mathrm{N}-\mathrm{CD}$ and $\mathrm{a}-\mathrm{CD}$, both by fs- and $\mu s-T A S$ (Figure S31). Conversely, the less efficient $g$-CD shows higher redshifted signals near $650 \mathrm{~nm}$. These observations suggest that photogenerated electrons absorbing near $500 \mathrm{~nm}$ are the more reactive excited state species, and that their formation is key to the observed high photocatalytic activity seen in $g-\mathrm{N}-\mathrm{CD}$ and not $g-\mathrm{CD}$. This result is in line with previous observations, and may reflect a higher reactivity of $\pi$ electrons from excited core states compared to surface states originating from $\mathrm{OH}$ groups. ${ }^{[30]}$

In contrast to EDTA, addition of $\mathbf{N i P}$ as an electron scavenger to CD solutions had no observable effect on the TAS. This indicates that, for the concentration of NiP used, electron transfer to NiP only proceeds by a reductive quenching mechanism following hole scavenging by EDTA (Figure 4). In accordance, the addition of NiP to CD + EDTA clearly accelerated the decay of the photoinduced absorption and further resulted in the appearance of a negative change in absorbance at $500 \mathrm{~nm}$ after tens of milliseconds (Figure $3 \mathrm{~d}$ ). A similar ground state bleach was observed in the case of Rudye $/ \mathrm{TiO}_{2} / \mathrm{NiP}$ and Ru-dye/NiP hybrid systems, and has been assigned to the reduction of $\mathbf{N i P}$ to form $\mathbf{N i P}^{-[24]}$ Negative signals were not observed at $800 \mathrm{~nm}$ where NiP shows no absorption, consistent with this assignment (Figure S27).

As observed with $g-\mathrm{N}-\mathrm{CD}$, the addition of EDTA to a-CD and $g$-CD solutions resulted in longer-lived $\mu$ s-TAS signals (Figures S32). However, the relative increase in $t_{50 \%}$ compared to phosphate solution was much less pronounced for a-CD and $g-C D$, suggesting lower charge transfer efficiencies. The formation of $\mathrm{NiP}^{-}$is estimated to be $15 \%$ more efficient with $\mathrm{g}-\mathrm{N}$ CD compared to a-CD (see Supporting Information). The enhanced efficiency of charge transfer from EDTA to $g-N-C D$ could be explained by the high proportion of pyridinic nitrogen dopants which have been previously reported to cause the formation of holes in graphitic structures. ${ }^{[13]}$ Oxygen quenching experiments showed a less pronounced quenching with $g-C D$ compared to $g-\mathrm{N}-\mathrm{CD}$ (Figure S33), further suggesting low formation yields of reactive photogenerated electrons in the absence of nitrogen doping. Accordingly, pyridinic nitrogen has also been associated with an increased density of $\pi$ states near the Fermi level in graphene. ${ }^{[12]}$ These results highlight that improved charge transfer reactivity (vs. a-CD) and improved photogeneration of reactive electrons (vs. $g-\mathrm{CD}$ ) underlie the higher photoactivity of $g-\mathrm{N}-\mathrm{CD}$.

In summary, we have reported herein the synthesis of graphitic and N-doped CDs using a SSP approach. Graphitized CDs ( $g$-CD and $g$-N-CD) show improved light absorption compared to amorphous particles (a-CD), resulting in increased specific activity (per mass $C D$ ) in photocatalytic $\mathrm{H}_{2}$ evolution systems. However, $g-\mathrm{N}-\mathrm{CD}$ also outperformed $g$-CD by a factor of 5 , with a record $C D$ specific activity of $7950 \mu \mathrm{mol}_{\mathrm{H} 2}\left(\mathrm{~g}_{\mathrm{CD}}\right)^{-1} \mathrm{~h}^{-}$ ${ }^{1}[25,26]$ The higher photoactivity of $g-N-C D$ stems from a combination of improved light harvesting ability without significantly compromising photogeneration of reactive electrons, charge transfer activity or recombination kinetics. Kinetic investigations revealed fast geminate recombination as a key limiting factor in CD photocatalytic systems, which needs to be addressed in future CD development. Nonetheless, the enhancement achieved in our second-generation CD solar $\mathrm{H}_{2}$ system represents a substantial advance and demonstrates the viability of a core doping strategy to enhance efficiency; the key limitation in existing $C D$ photosensitizers.

\section{Acknowledgements}

This work was supported by an Oppenheimer PhD scholarship (to BCMM), a Poynton PhD scholarship (to GAMH), a Marie Curie postdoctoral fellowship (to CAC), a FRQNT postdoctoral fellowship (to RG), the ERC Intersolar project (No. 291482; to JRD), the Christian Doppler Research Association (Austrian Federal Ministry of Science, Research, and Economy and the National Foundation for Research, Technology and Development) and OMV (to ER). XPS was taken at the NEXUS facility, UK. Xin Fang is acknowledged for conducting AFM and Khoa H. Ly for helpful discussions.

Keywords: carbon dots $\bullet$ doping $\bullet$ light harvesting $\bullet$ photocatalysis $\cdot$ excited state dynamics

[1] S. Y. Lim, W. Shen, Z. Gao, Chem. Soc. Rev. 2015, 44, 362-381.

[2] K. A. Shiral Fernando, S. Sahu, Y. Liu, W. K. Lewis, E. A. Guliants, A. Jafariyan, P. Wang, C. E. Bunker, Y.-P. Sun, ACS Appl. Mater. Interfaces 2015, 7, 8363-8376.

[3] B. C. M. Martindale, G. A. M. Hutton, C. A. Caputo, E. Reisner, J. Am. Chem. Soc. 2015, 137, 6018-6025.

[4] A. Cayuela, M. L. Soriano, C. Carrillo-Carrión, M. Valcárcel, Chem. Commun. 2016, 52, 1311-1326.

[5] B. J. Moon, Y. Oh, D. H. Shin, S. J. Kim, S. H. Lee, T. W. Kim, M. Park, S. Bae, Chem. Mater. 2016, 28, 1481-1488.

[6] X. Li, S. Zhang, S. A. Kulinich, Y. Liu, H. Zeng, Sci. Rep. 2014, 4, 4976 .

[7] Y. Song, S. Zhu, S. Zhang, Y. Fu, L. Wang, X. Zhao, B. Yang, J. Mater. Chem. C 2015, 3, 5976-5984.

[8] M. K. Barman, B. Jana, S. Bhattacharyya, A. Patra, J. Phys. Chem. C 2014, 118, 20034-20041.

V. Strauss, J. T. Margraf, C. Dolle, B. Butz, T. J. Nacken, J. Walter, 
W. Bauer, W. Peukert, E. Spiecker, T. Clark, D. M. Guldi, J. Am. Chem. Soc. 2014, 136, 17308-17316.

[10]

F. Li, C. Liu, J. Yang, Z. Wang, W. Liu, F. Tian, RSC Adv. 2014, 4, 3201-3205.

[11] Y. Wang, A. Hu, J. Mater. Chem. C 2014, 2, 6921-6939.

[12] Z. Luo, S. Lim, Z. Tian, J. Shang, L. Lai, B. Macdonald, C. Fu, Z Shen, T. Yu, J. Lin, J. Mater. Chem. 2011, 21, 8038-8044.

[13] F. Joucken, Y. Tison, J. Lagoute, J. Dumont, D. Cabosart, B. Zheng V. Repain, C. Chacon, Y. Girard, A. R. Botello-Méndez, S. Rousset, R. Sporken, J.-C. Charlier, L. Henrard, Phys. Rev. B 2012, 85 161408.

[14] Y. Aksu, M. Driess, Angew. Chem. Int. Ed. 2009, 48, 7778-7782.

[15] Y.-H. Lai, D. W. Palm, E. Reisner, Adv. Energy Mater. 2015, 5, 1501668.

[16] H. Peng, J. Travas-Sejdic, Chem. Mater. 2009, 21, 5563-5565.

[17] G. A. M. Hutton, B. Reuillard, B. C. M. Martindale, C. A. Caputo, C. W. J. Lockwood, J. N. Butt, E. Reisner, J. Am. Chem. Soc. 2016, $138,16722-16730$.

[18] X. Wang, Z. Hou, T. Ikeda, K. Terakura, J. Phys. Chem. C 2014 118, 13929-13935

[19] S. Sarkar, M. Sudolská, M. Dubecký, C. J. Reckmeier, A. L. Rogach, R. Zbořil, M. Otyepka, J. Phys. Chem. C 2016, 120, 1303-1308.

[20] S. R. Kelemen, M. L. Gorbaty, P. J. Kwiatek, Energy Fuels 1994, 8, 896-906. [21] K. Gong, F. Du, Z. Xia, M. Durstock, L. Dai, Science 2009, 323,

[22] N. Dhenadhayalan, K.-C. Lin, R. Suresh, P. Ramamurthy, J. Phys. Chem. C 2016, 120, 1252-1261.

[23] C. J. Reckmeier, Y. Wang, R. Zboril, A. L. Rogach, J. Phys. Chem. C 2016, 120, 10591-10604.

[24] M. A. Gross, A. Reynal, J. R. Durrant, E. Reisner, J. Am. Chem. Soc 2014, 136, 356-366.

[25] P. Yang, J. Zhao, J. Wang, H. Cui, L. Li, Z. Zhu, RSC Adv. 2015, 5, 21332-21335.

[26] X. Xu, Z. Bao, G. Zhou, H. Zeng, J. Hu, ACS Appl. Mater. Interfaces 2016, 8, 14118-14124

[27] H. Kasap, C. A. Caputo, B. C. M. Martindale, R. Godin, V. W.-H Lau, B. V. Lotsch, J. R. Durrant, E. Reisner, J. Am. Chem. Soc. 2016, 138, 9183-9192.

[28] A. J. Cowan, J. R. Durrant, Chem. Soc. Rev. 2013, 42, 2281-2293.

[29] L. Wang, S.-J. Zhu, H.-Y. Wang, S.-N. Qu, Y.-L. Zhang, J.-H. Zhang, Q.-D. Chen, H.-L. Xu, W. Han, B. Yang, H.-B. Sun, ACS Nano 2014, 8, 2541-2547.

[30] J. P. Guin, S. K. Guin, T. Debnath, H. N. Ghosh, Carbon 2016, 109, 517-528.

[31] L. Sui, W. Jin, S. Li, D. Liu, Y. Jiang, A. Chen, H. Liu, Y. Shi, D. Ding, M. Jin, Phys. Chem. Chem. Phys. 2016, 18, 3838-3845.

[32] G. D. Scholes, G. Rumbles, Nat. Mater. 2006, 5, 683-696.

[33] Y. Deng, D. Zhao, X. Chen, F. Wang, H. Song, D. Shen, Chem. Commun. 2013, 49, 5751-5753.

[34] K. Jiang, L. Zhang, J. Lu, C. Xu, C. Cai, H. Lin, Angew. Chem. Int Ed. 2016, 55, 7231-7235. 


\section{COMMUNICATION}

Carbon dots are investigated for solar $\mathrm{H}_{2}$ production and a number of critical structure-activity relationships are determined for the first time. Nitrogendoping of the core structure is established as a strategy to enhance charge transfer reactions in graphitic carbons dots, which demonstrate strong light absorption. Transient absorption spectroscopy has provided great insight into the mechanisms of photocatalytic activity and identified key performance limiting factors.

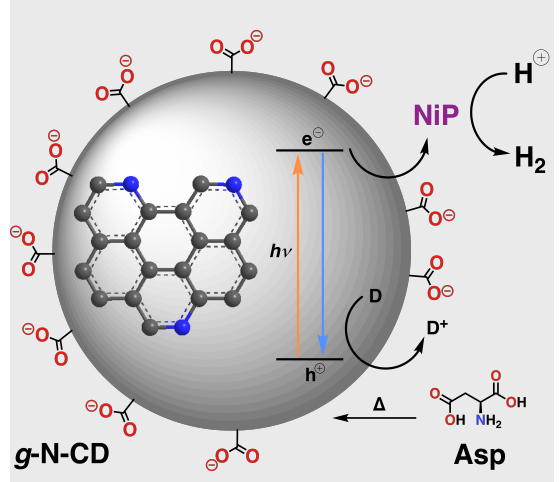

Author(s), Corresponding Author(s)*

Page No. - Page No.

Title 